\title{
Aligning monitoring design with fishery decision-making: examples of management strategy evaluation for reef-associated fisheries
}

\author{
William J. HARFORD ${ }^{\mathrm{a}}$ and Elizabeth A. BABCOCK \\ University of Miami, Rosenstiel School of Marine and Atmospheric Science, 4600 Rickenbacker Causeway, Miami, Fl, 33149, USA
}

Received 17 August 2015; Accepted 3 December 2015

\begin{abstract}
Limitations in data quantity and quality are common in fisheries management and affect whether and how stock assessments are carried out. We demonstrate the applicability of spatially-explicit management strategy evaluation (MSE) for connecting sampling designs of substrate-associated fishes in highly heterogeneous habitats to evaluation of stock status and to decision-making. Simulation-based analysis is conducted to understand how survey precision influences assessment and decision-making performance for a black grouper (Mycteroperca bonaci) fishery within the Florida Keys reef tract. Rather than delving into statistical principles of survey design, we examine the performance of well-designed surveys in the currency of achieving fishery management objectives. In practical terms, our approach draws attention to subtle aspects of how data precision can affect achievement of management objectives. Our discussion centers on the idea that the interconnected properties of survey precision, stock assessment, and precaution taken in decision-making must be jointly considered in fisheries management policies.
\end{abstract}

Keywords: Natural resource monitoring / survey design / fishery management / simulation model

\section{Introduction}

Understanding whether resource monitoring programs adequately support management decisions is fundamental to fisheries science. A primary concern is how different kinds of data inform stock status determination and support management actions aimed at controlling exploitation rates (Magnusson and Hilborn 2007). Of related concern is whether resource surveys are designed with sufficient precision (low variance) to support decision-making (Houk and van Woesik 2013; Olsen et al. 1999). Together, types of data inputs and data precision affect accuracy and precision of stock status determination, management reference point calculations, and the scientific merit and certainty associated with management decisions. It is therefore valuable to consider the collective performance of management strategies beginning with monitoring designs and ending with management decision-making.

A simulation-based approach that emphasizes these interconnections is known as management strategy evaluation (Butterworth and Punt 1999; Hertz and Thomas 1983; Punt et al. 2014; Sainsbury et al. 2000). A fisheries management strategy consists of a monitoring design that describes how data are collected, scientific analysis that typically consists of a stock assessment, and a set of decisions for adjusting management tactics (Sainsbury et al. 2000). MSE simulates

a Corresponding author: wharford@rsmas . miami .edu a management system in its entirety, so that MSE can be used to link spatial-temporal fish dynamics, monitoring protocols, fishery behavior, and decision-making (Butterworth et al. 2010; Pelletier and Mahévas 2005; Sainsbury et al. 2000). Management strategy performance is evaluated in terms of whether pre-stated management objectives are likely to be achieved. When designing monitoring protocols, MSE is appealing because survey design questions can be addressed in performance currencies that are directly relevant to resource managers. Further, where changes or improvement to monitoring protocols are not feasible, MSE can be used to identify management strategies that are robust to data reliability issues. MSE is an attractive approach for investigating the effects of monitoring on overall management strategy performance because the effects of data inputs are propagated through the management system.

We use two examples to illustrate the integration of survey design considerations with fishery decision-making through simulated MSE. The first example evaluates the role of biomass survey precision in a management strategy aimed at optimizing fishery yields using a stock assessment model. The second example describes connections between survey precision and a model-free (or empirical) management strategy that does not rely on a stock assessment. Our examples are constructed using a spatially-explicit individual-based model (IBM) that simulates spatial-temporal dynamics of substrate associated fishes within the Florida Keys coral reef ecosystem 


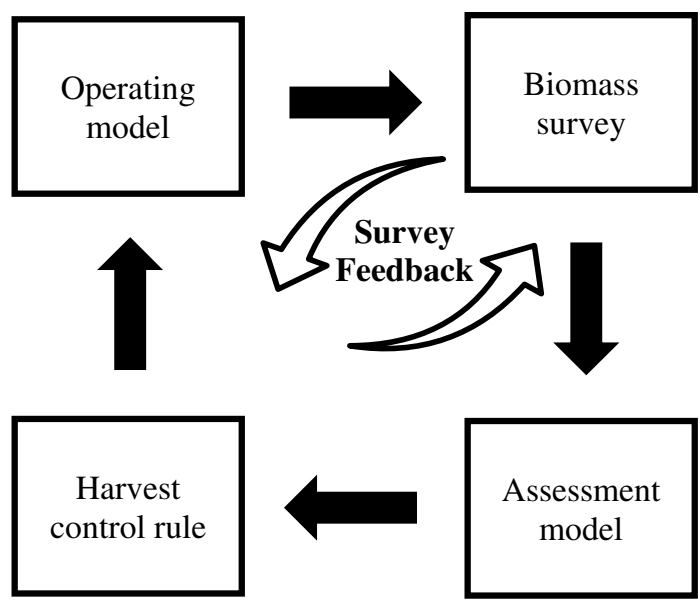

Fig. 1. Simulation framework for management strategy evaluation.

(Richards et al. 2011; Smith et al. 2011). IBMs have been previously developed to describe fish stock dynamics (DeAngelis et al. 1991; Rose et al. 1999; van Winkle et al. 1998) and have sometimes been used to evaluate fisheries monitoring and assessment procedures (Codling 2008; McDonald et al. 2008; Miethe et al. 2009; Saul et al. 2012). Of the advancements made in describing fish stock dynamics, IBMs that simulate areal distributions and movement of fish hold considerable potential for evaluating spatial aspects of fisheries management (Huse 2001; Huse and Giske 1998; Railsback et al. 1999; Tyler and Rose 1994). In addition, IBMs are well suited to incorporating biological characteristics that are otherwise difficult to incorporate in numerical simulations, like individual variation in size and growth rates (Alós et al. 2010; Bunnell and Miller 2005; Hart 2001; Russo et al. 2009).

A unique component of our IBM is simulation of the survey implementation process, which we base on a Neyman effort allocation scheme (Cochran 1977; Thompson 2012). Allocation of sampling effort is based on feedback from previous sampling events. Consequently, two feedback loops operate concurrently in our simulations: survey implementation and management decisions that modify fishery tactics (Fig. 1). Our two MSE examples illustrate the interconnected aspects of the often disparate processes of statistical sampling design and fishery management decision-making. The examples complement one another because they highlight the use of MSE for reconciling data limitations with expectations about achieving fishery objectives (Dowling et al. 2015). They contrast a datamoderate circumstance aimed at achieving MSY-based management objectives with a data-limited circumstance aimed at sustainable, but perhaps not optimal, catch rates. Advancement of data-limited stock assessment has been rapid, but there remains a lack of clarity about how data-limited metrics and decision-making processes should collectively operate (Cope and Punt 2009; Martell and Froese 2012). MSE can help to evaluate whether monitoring and decision-making will together lead to repetitive errors in decision-making or whether reasonable success can be achieved in the face of combined challenges associated with monitoring, fishery stock assessment, and decision-making.

\section{Spatially explicit IBM}

Purpose - an individual-based model (IBM) simulated an age-structured fish stock whose distribution was associated with a spatially-heterogeneous coral reef environment. In the following sections, the simulation framework is described according to the Overview, Design concepts, and Details (ODD) protocol for IBM development (Grimm et al. 2006).

State variables and scales - the simulation framework comprised four main components: a coral reef environment, individual fish, a fishery, and a biomass survey. The coral reef environment consisted of artificial landscapes that had vertical relief properties similar to those found in the $885 \mathrm{~km}^{2}$ spatial domain Florida Keys reef tract. Vertical relief (m) describes the height of benthic structures, including coral and rocky outcrops and was utilized because reef fish distributions are known to be correlated with substrate characteristics (Chapman and Kramer 1999; Farmer and Ault 2011; Sluka et al. 2001). Individual fish were characterized by age, length, whole weight, and location. The simulated fishery was subject to a minimum harvest length and all individuals were equally susceptible to harvest regardless of location in the environment. Biomass surveys were generated by simulating stratified random sampling within artificial landscapes.

Process overview and scheduling - during each monthly time step, model processes occurred in the following order: growth, recruitment, spawning, and mortality. Spawning occurred only at the beginning of the year and recruits were added at the beginning of the following year. The simulated fishery operated during the last eight months of each year. Simulations were constructed in the Java programming language using the multi-individual simulation library MASON (Luke et al. 2005). With the exception of spawning and recruitment, processes were carried out through synchronous updating of state variables.

Initialization and inputs - each simulation run was initialized with a different random seed. At the beginning of each simulation, a unique realization of the coral reef environment was generated. Prior to using the simulated fish stock in the MSE, model processes were initially stepped forward for 100 years at a constant fishing mortality rate to generate an already exploited stock that was reduced to $50 \%$ of its unfished spawning biomass. Model inputs were (1) statistical properties of vertical relief of the Florida Keys Reef tract, (2) life history characteristics of black grouper (Mycterperca bonaci), a large economically important species of the family Serranidae (Tables 1 and 2), and (3) a stochastic stock-recruitment function.

Submodels - Artificial landscapes were generated because actual mapping data at fine spatial resolution was only available for parts of the Florida Keys reef tract (Smith et al. 2011). Artificial landscapes were generated as fractional Brownian surfaces. Two-dimensional fractional Brownian surfaces exist within a class of neutral landscape models employed in landscape ecology and can be used to capture the spatial properties of actual landscapes (Keitt 2000; Li et al. 2004; Peitgen and Saupe 1988; Stein 2002; With and King 1997). Spatially autocorrelated grid cell values were simulated using the RandomFields package in the statistical computing software R (R Development Core Team 2012; Schlather et al. 2013). Simulated landscapes consisted of 13630 grid cells of $200 \mathrm{~m}$ by $200 \mathrm{~m}$ 
Table 1. Reproductive processes and parameters used in simulating fish population dynamics. Dashes indicate derived quantities, $i$ is individual identifier, and $t$ is annual time step.

\begin{tabular}{|c|c|c|c|c|}
\hline & Equations and algorithms & & Parameters & Values \\
\hline \multirow[t]{7}{*}{$\begin{array}{c}\text { Annual } \\
\text { recruitment }\end{array}$} & \multirow{2}{*}{$R_{t}=\frac{B_{t-1}}{a+b B_{t-1}} \exp \left(\operatorname{Normal}\left(0, \sigma_{R}^{2}\right)\right)$} & $R_{t}$ & Annual recruits & - \\
\hline & & $B_{t}$ & $\begin{array}{c}\text { Spawning } \\
\text { biomass }\end{array}$ & - \\
\hline & \multirow{5}{*}{$b=\frac{5 z-1}{4 z R_{0}}$} & $a, b$ & $\begin{array}{l}\text { Stock-recruitment } \\
\text { parameters }\end{array}$ & - \\
\hline & & $R_{0}$ & $\begin{array}{l}\text { Unfished } \\
\text { recruitment }\end{array}$ & 50000 \\
\hline & & $z$ & Steepness & 0.75 \\
\hline & & $\widetilde{S}$ & Unfished SBR & 45 \\
\hline & & $\sigma_{R}$ & $\begin{array}{c}\text { Log-scale } \\
\text { standard } \\
\text { deviation }\end{array}$ & 0.6 \\
\hline $\begin{array}{c}\text { Spawning } \\
\text { biomass }(\mathrm{kg}) \\
\end{array}$ & $B_{t}^{s}=\sum_{i} W_{i}$ Mat $_{i}$ Female $_{i}$ & $B_{t}^{s}$ & $\begin{array}{c}\text { Spawning } \\
\text { biomass }\end{array}$ & - \\
\hline $\begin{array}{l}\text { Proportion } \\
\text { mature }\end{array}$ & $\operatorname{Mat}_{i}\left(L_{i}\right)=\frac{1}{1+\exp \left(-\kappa\left(L_{i}-L_{\mathrm{mat}}\right)\right)}$ & $\begin{array}{c}K \\
L_{\mathrm{mat}}\end{array}$ & $\begin{array}{c}\text { Curvature } \\
\text { Inflection (mm) }\end{array}$ & $\begin{array}{l}0.0139 \\
832.7\end{array}$ \\
\hline $\begin{array}{c}\text { Sex } \\
\text { transition }\end{array}$ & $\operatorname{Female}_{i}\left(L_{i}\right)=\frac{1}{1+\exp \left(-\theta\left(L_{i}-L_{f}\right)\right)}$ & $\begin{array}{c}\theta \\
L_{f}\end{array}$ & $\begin{array}{c}\text { Curvature } \\
\text { Inflection }(\mathrm{mm})\end{array}$ & $\begin{array}{l}-0.0158 \\
1213.7\end{array}$ \\
\hline
\end{tabular}

Table 2. Growth and mortality processes and parameters. Dashes indicate derived quantities, $i$ is individual identifier, and $t$ is annual time step.

\begin{tabular}{|c|c|c|c|c|}
\hline Processes & Equations and algorithms & & Parameters & Values \\
\hline \multirow{9}{*}{$\begin{array}{c}\text { Growth } \\
\text { in total } \\
\text { length } \\
(\mathrm{mm})\end{array}$} & \multirow[b]{2}{*}{$L_{i}(t)=L_{\infty, i}\left(1-\exp \left(-K_{i}\left(t_{i}-t_{0}\right)\right)\right)$} & $\bar{L}(a)$ & Total length & - \\
\hline & & $L_{\infty, i}$ & Asymptotic length & - \\
\hline & \multirow{2}{*}{$L_{\infty, i} \sim N\left(\mu_{\infty}, \sigma_{\infty}^{2}\right)$} & $K_{i}$ & Brody growth coefficient $\left(\mathrm{yr}^{-1}\right)$ & - \\
\hline & & $\mu_{\infty}$ & Mean asymptotic & 1362 \\
\hline & \multirow{5}{*}{$K_{i} \sim \Gamma\left(s_{K}, r_{K}\right)$} & & Variance & \\
\hline & & $\sigma_{\infty}$ & asymptotic length & 38 \\
\hline & & $s_{K} / r_{K}$ & $\begin{array}{l}\text { Mean growth } \\
\text { coefficient }\left(\mathrm{t}^{-1}\right)\end{array}$ & 0.138 \\
\hline & & $s_{K} / r_{K}^{2}$ & $\begin{array}{c}\text { Variance } \\
\text { growth coefficient }\end{array}$ & 0.014 \\
\hline & & $t_{0}$ & Coefficient & -0.87 \\
\hline \multirow{3}{*}{$\begin{array}{l}\text { Whole weight } \\
\text { conversion } \\
(\mathrm{kg})\end{array}$} & \multirow{3}{*}{$W_{i}=a_{W} L_{i}^{b_{W}}$} & $W_{i}$ & Total weight & - \\
\hline & & $a_{W}$ & Factor & $4.46 \times 10^{-9}$ \\
\hline & & $b_{W}$ & Factor & 3.18 \\
\hline \multirow{2}{*}{$\begin{array}{r}\text { Mortality } \\
\left(\text { year }^{-1}\right)\end{array}$} & \multirow[t]{2}{*}{$M_{i}\left(L_{i}\right)=M_{\mathrm{Ref}} \frac{L_{\mathrm{Ref}}}{L_{i}}$} & $M_{\text {Ref }}$ & $\begin{array}{c}\text { Reference } \\
\text { mortality }\left(\mathrm{t}^{-1}\right)\end{array}$ & 0.12 \\
\hline & & $L_{\text {Ref }}$ & Reference length & 832.7 \\
\hline
\end{tabular}

dimension $\left(545.2 \mathrm{~km}^{2}\right)$. The landscapes represented three spatial properties of the Florida Keys Reef tract (Fig. 2). First, the spatial distribution of contiguous grid cells followed the irregularly shaped cross-shelf distribution of reef habitats that extend approximately $250 \mathrm{~km}$ between Key West and Miami, Florida. Second, simulated spatial distribution of vertical relief reflected empirical measures of spatial autocorrelation among neighboring grid cells. And third, the irregularly shaped grid was divided into cross-shelf habitat strata reflecting measured means and variances in vertical relief across reef formation types, including inshore patch reefs and offshore fore reefs.

Newly recruiting individuals were added to the landscape in proportion to vertical relief, $V_{c}$, in each cell, $c$, using a dis- crete choice logit model (Train 2002):

$$
p_{c}=\frac{\exp \left(\beta V_{c}\right)}{\sum_{c} \exp \left(\beta V_{c}\right)},
$$

where $\beta$ was a coefficient describing the slope of the relationship between occupancy probability and vertical relief (Harford et al. 2016). Total age-1 recruits was calculated using a Beverton and Holt function with lognormally-distributed process error $\left(\sigma_{R}\right.$; Table 1$)$.

Growth in length occurred according to the function described by von Bertalanffy (1938). Stochastic growth was incorporated by assigning each recruit a unique growth trajectory 


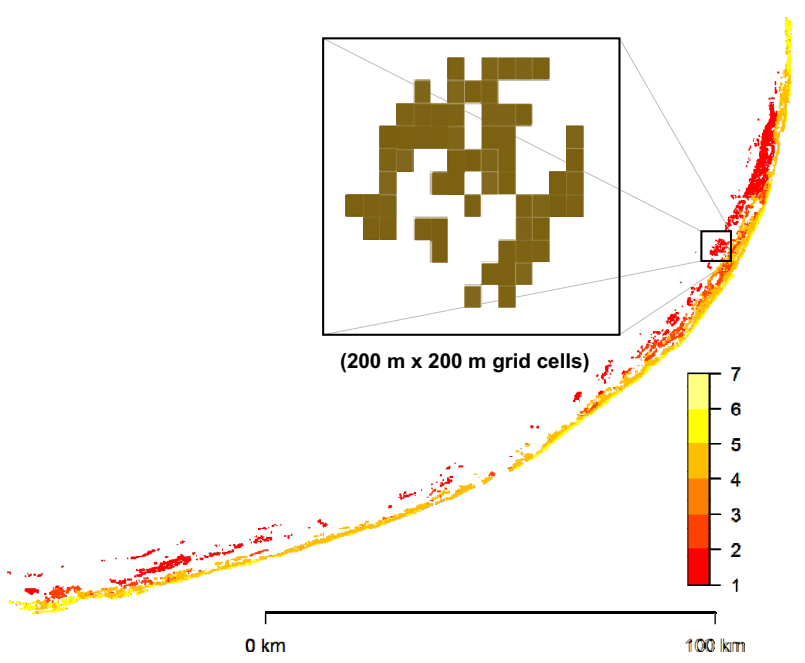

Fig. 2. Spatial hierarchy of the artificial landscape of the Florida Keys coral reef ecosystem. Scale (numbers 1 to 7 ) refers to the cross-shelf habitat strata used to distribute individual fish and to stratify survey effort: (1) low-medium rugosity inshore patch reefs, (2) low-medium rugosity mid-channel patch reefs, (3) low-medium rugosity offshore patch reefs, (4) high rugosity offshore patch reefs, (5) low-medium rugosity outer fore reef, (6) low-medium rugosity outer fore reef, and (7) high rugosity outer fore reef.

that was derived from empirical data (Harford 2014). Assigning individuals unique growth trajectories was not intended to imply that individual-level growth variation arose strictly from intrinsic factors; rather, the approach was intended to reproduce an empirical pattern. Unique growth trajectories were assigned by varying asymptotic length, $L_{\infty}$, and the Brody growth coefficient, $K$, according to Gaussian and gamma distributions, respectively (Table 2). Age-1 recruits were each individually assigned $L_{\infty}$ and $K$, thus variable lengths-atrecruitment occurred as well as individual growth trajectories. Growth in length was a function of age, however, other life history characteristics (i.e. weight, natural mortality, maturity, and sexual transition) were functions of length. Thus, individual growth variation introduced natural process variability to the timing of life history events like maturation. Incorporating individual growth variation was also useful because the simulated fishery was regulated, in part, through minimum harvest length restrictions, as are actual grouper fisheries, and thus incorporating individual variation produced more realistic exploitation patterns (SEDAR 2010). Fish movement was not explored in the simulations as many reef-associated fishes tend to exhibit low mobility.

Survival was a function of length-based $(L)$ natural mortality rate, $M$, and fishing mortality, $F$, and was converted into survival probability, $S=\exp (-M(L)-F)$. Natural mortality was specified as an inverse function of length and scaled so that average lifetime natural mortality was 0.09 year $^{-1}$ based on black grouper longevity of 33 years (Table 2; Alagaraja 1984; Lorenzen 1996). Each individual survived to the following month if their survival probability was greater than a randomly generated number between 0 and 1 . When an individual did not survive, mortality was attributed to fishing if a second random draw was less than the harvest fraction,
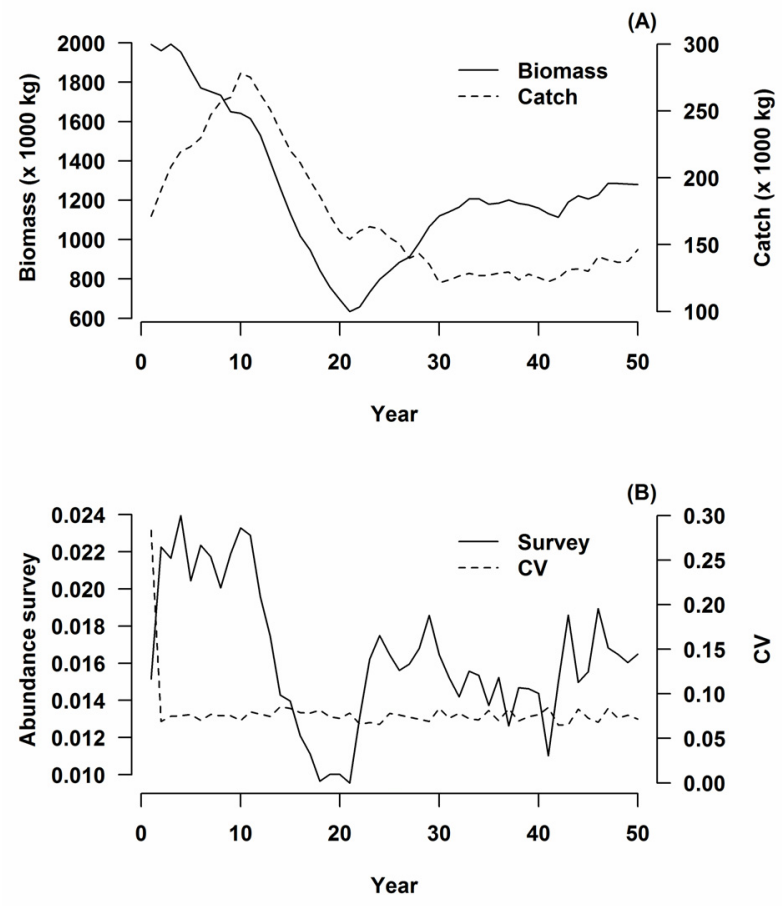

Fig. 3. Example time series of biomass and catch (A) and biomass survey (B).

$F /(F+M(L))$. The fishery was subject to a minimum harvest length of $610 \mathrm{~mm}$, which is consistent with actual U.S. regulation of black grouper (SEDAR 2010), and the fishery was simulated without implementation error.

The biomass survey was designed using an optimality procedure for allocating survey effort (Cochran 1977; Thompson 2012). Sampling effort consisted of the total number of $200 \mathrm{~m}$ by $200 \mathrm{~m}$ grid cells that were sampled. Using the cross-shelf habitat strata of the artificial landscapes as sampling strata, inputs to the optimality procedure were: a running average of within-strata variances in density from the previous three years, the number of grid cells in each stratum, and the target observation error $(\mathrm{CV})$ of the mean density estimator. From these inputs, survey effort and allocation among strata was calculated that was expected to achieve the target observation error (Table 3; Cochran 1977; Thompson 2012). Thus, the survey design maintained a target $\mathrm{CV}$ across changes in stock biomass by adjusting sampling effort and spatial allocation of effort (Fig. 3B). Consequently, observation noise was not simply added to the survey of true stock density; rather, a realistic survey design was simulated, including calculating future sampling effort based on previous (and potentially imprecise) surveys (e.g. Smith et al. 2011). Survey catchability within sampled grid cells was set to 0.01 .

\subsection{An example of an MSY-based harvest control rule}

We used a simple management strategy based upon Schaefer surplus production to introduce connections between data inputs, fishery reference point estimation, stock status determination, and decision-making. Simulated surveys 
Table 3. Equations used in optimality procedure for survey effort allocation for stratified random sampling, described by Cochran (1977) and Thompson (2012). $h$ is cross-shelf habitat strata, $d$ is sampling-domain-wide estimate, $T$ is the number of strata.

\begin{tabular}{ccc}
\hline Parameter & Equation & Definition \\
\hline $\bar{U}_{h}$ & $\bar{U}_{h}=\frac{1}{g_{h}} \sum_{i=1}^{g_{h}} U_{h, i}$ & Sample mean for stratum $h$ \\
$g_{h}$ & $\operatorname{var}_{h}=\frac{1}{g_{h}-1} \sum_{i=1}^{g_{h}}\left(U_{h, i}-\bar{U}_{h}\right)^{2}$ & Grid cells sampled in stratum $h$ \\
$\operatorname{var}_{h}$ & $\bar{U}_{d}=\sum_{h=1}^{T} w_{h} \bar{U}_{h}$ & Sample variance for stratum $h$ \\
$\bar{U}_{d}$ & $w_{h}=\frac{G_{h}}{\sum_{h=1}^{T} G_{h}}$ & Sampling-domain-wide mean biomass density \\
$w_{h}$ & $g^{*}=\frac{\left(\sum_{h=1}^{T} w_{h} \sqrt{\operatorname{var}_{h}}\right)^{2}}{\operatorname{var}^{*}+\frac{1}{M_{h} G_{h}} \sum_{h=1}^{T} w_{h} \operatorname{var}_{h}}$ & Stratum weight \\
$\operatorname{var}\left[\overline{U_{d}}\right]$ & $\operatorname{var}\left[\bar{U}_{d}\right]=\sum_{h=1}^{T} w_{h}^{2}\left(\frac{G_{h}-g_{h}}{G_{h}}\right) \frac{\operatorname{var}_{h}}{g_{h}}$ & Total number of grid cells in stratum $h$ \\
$g^{*}$ & $\operatorname{var}^{*}=C V^{*} \bar{U}_{d}$ & Total number of samples required to achieve target variance \\
$\operatorname{var}^{*}$ & $g_{h}^{*}=g^{*} \frac{w_{h} \sqrt{\operatorname{var}_{h}}}{\sum_{h=1}^{T} w_{h} \sqrt{\operatorname{var}_{h}}}$ & Target coefficient of variation of domain wide biomass density estimate \\
$g_{h}^{*}$ & Optimal allocation of total samples among strata \\
\hline
\end{tabular}

and a model-based stock assessment procedure were used to estimate current stock status and maximum sustainable yield (MSY) reference points. Surplus production modeling is sometimes considered a simplistic representation of stock dynamics; however, its simplicity contributes to its importance in fisheries management (Zhang 2013). We therefore used surplus production in this example to demonstrate the capacity for simple biomass dynamic models to be subsequently linked to harvest control rules that attempt to achieve MSY-based fishery management objectives.

MSE procedure - after initializing the IBM, 50-year sequences of biomass depletion followed by modest recovery were simulated because this type of biomass trend contains information needed to estimate both unfished biomass and the intrinsic rate of increase via a surplus production model (Fig. 3A; Hilborn and Walters 1992). During each simulation run, fishery-independent surveys were concurrently implemented, each designed to achieve a constant CV between 0.1 and 0.5 . Time series of yields and survey indices were used in the stock assessment model to estimate reference points and were compared to the true reference points obtained from the IBM. The Schaefer (1954) surplus production can be written:

$$
B_{t+1}^{E}=B_{t}^{E}+r B_{t}^{E}\left(1-\frac{B_{t}^{E}}{B_{0}}\right)-Y_{t}^{w},
$$

where $r$ is intrinsic rate of increase, and $B_{0}$ is unfished biomass, and $Y^{w}$ is yield in weight and $B^{E}$ is exploitable biomass at time $t$. In fitting, surveys were specified as having log-normally distributed error structure $\left(U_{t} \sim \operatorname{lognormal}\left(q_{U} B_{t}^{E}, \sigma_{U}^{2}\right)\right)$, where $q_{U}$ is a proportionality constant and $\sigma_{U}^{2}$ is residual variance. Statistical fitting was carried out using AD Model Builder by minimizing a concentrated negative log-likelihood function

$$
\begin{aligned}
& (-\log \Lambda): \\
& -\log \Lambda=\frac{n}{2} \log \left(\frac{1}{n} \sum\left(\log \left(\frac{U_{t}}{B_{t}^{E}}\right)-\frac{1}{n} \sum \log \left(\frac{U_{t}}{B_{t}^{E}}\right)\right)^{2}\right),
\end{aligned}
$$

where $q$ and $\sigma_{U}^{2}$ were concentrated out of the log-likelihood by specifying these parameters at their maximum likelihood estimators, thus leaving point estimates of $r, B_{0}$ and initial biomass as a fraction of $B_{0}$ to be estimated (Fournier et al. 2012; Walters and Ludwig 1994).

MSE results - we found that survey precision affected bias and precision of MSY estimates. Surveys with lower CVs produced more accurate MSY estimates, and as survey indices became less precise estimation uncertainty of MSY was inflated (Figs. 4B, 4D, 4F, 4H). Across all levels of survey precision, MSY estimator precision was not correlated with bias, suggesting that biased estimates were not necessarily imprecise and vice versa. Since MSY $=r B_{0} / 4$, we examined whether estimation uncertainty in $r$ or $B_{0}$ was contributing to uncertainty in MSY. Correlation between precision of $B_{0}$ and $r$ was high (Pearson's correlation coefficient $=0.85$ ). Accordingly, precision of MSY was affected by precision of $r$ (Pearson's correlation coefficient $=0.54$ ) and by precision of $B_{0}$ (Pearson's correlation coefficient $=0.84)$. Our findings also demonstrated that MSY tended to be overestimated at all levels of survey precision (Fig. 4). This result reflects the differences between the complex individual-based stock dynamics used to simulate the fish stock and the simplified assessment model used to estimate reference points. In addition, overestimates of MSY are often obtained using surplus production modeling for species with low intrinsic rates of increase, like black grouper (Hilborn 1979; Mohn 1980; Zhang 2013). True biomass expected to produce MSY was $\cong 0.3 B_{0}$ in our IBM and not $=0.5 B_{0}$ that is assumed by the formulation of the Schaefer surplus production model. 

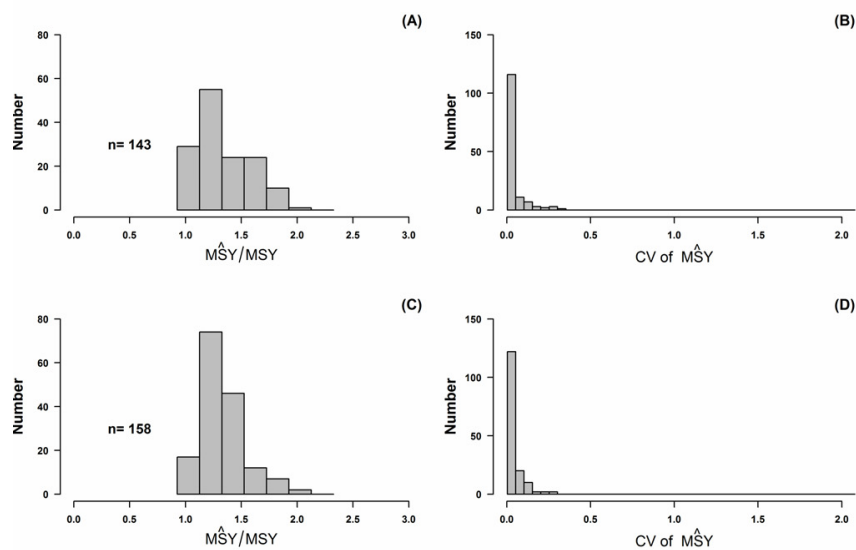

$$
\text { (1) }
$$
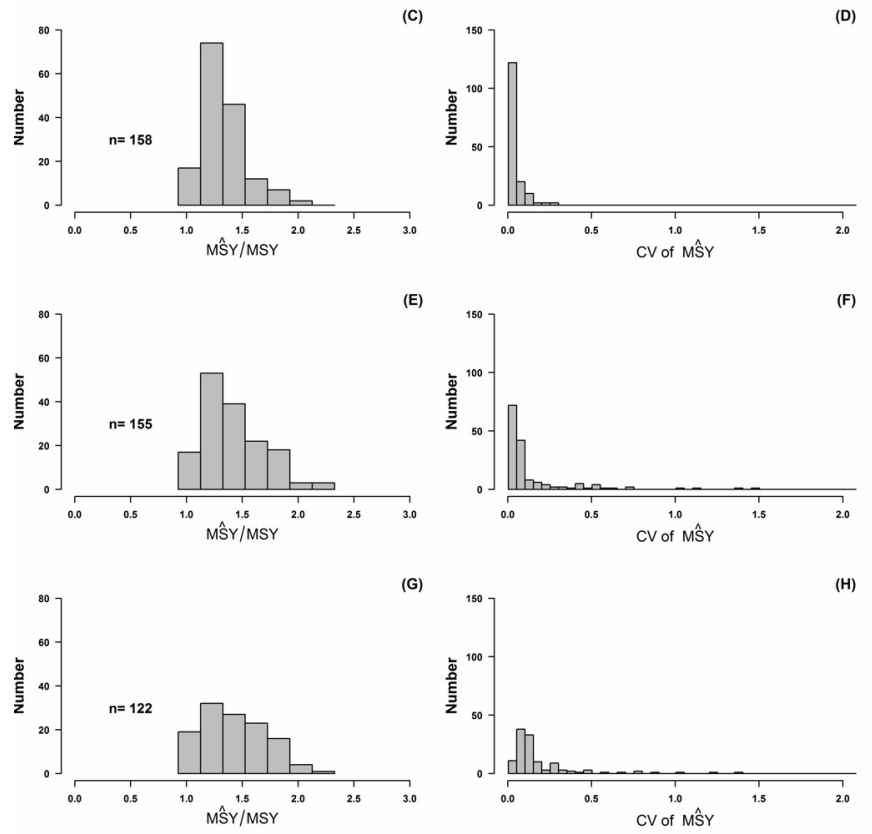

Fig. 4. Estimated maximum sustainable yield $(\widehat{M S Y})$, divided by the true value with associated estimator precision reported as coefficient of variation $(\mathrm{CV})$. Shown are estimates obtained from fitting a Schaefer production model to survey density recorded without observation error $(\mathrm{A}, \mathrm{B})$, and survey target $\mathrm{CV}$ of $0.1(\mathrm{C}, \mathrm{D})$, survey target $\mathrm{CV}$ of 0.3 (E,F), and survey target $\mathrm{CV}$ of $0.5(\mathrm{G}, \mathrm{H})$. n refers to the number of successful fits obtained from 200 simulated datasets.

Having explored precision and bias of reference point estimation, we simulated harvest control rules (HCRs) that linked surveys and stock assessment to decision-making. In practical terms, we asked whether biased and imprecise management quantities can still lead to reasonable achievement of management objectives or whether there would be a considerable chance of management failure. MSE performance was measured in terms of whether HCRs would (1) guide biomass towards the estimated target of $0.5 B_{0}$, which is the biomass level associated with MSY in the Schaefer surplus production model, and (2) avoid biomass levels associated with overfished status, which was specified as biomass below $0.2 B_{0}$. After model initialization and a 50 year depletion-rebuilding period, a HCR was used to adjust annual fishing effort. The adjusted effort level was implemented and the simulation was stepped ahead one year (in one month increments). Then, time series of catch and survey biomass were updated and an assessment was conducted with the now incrementally longer time series. HCRs were implemented in this manner for 50 years. An MSY HCR specified $F_{\text {target }}=F_{M S Y}=0.5 r$; a value which was estimated each year from the surplus production model fitted to

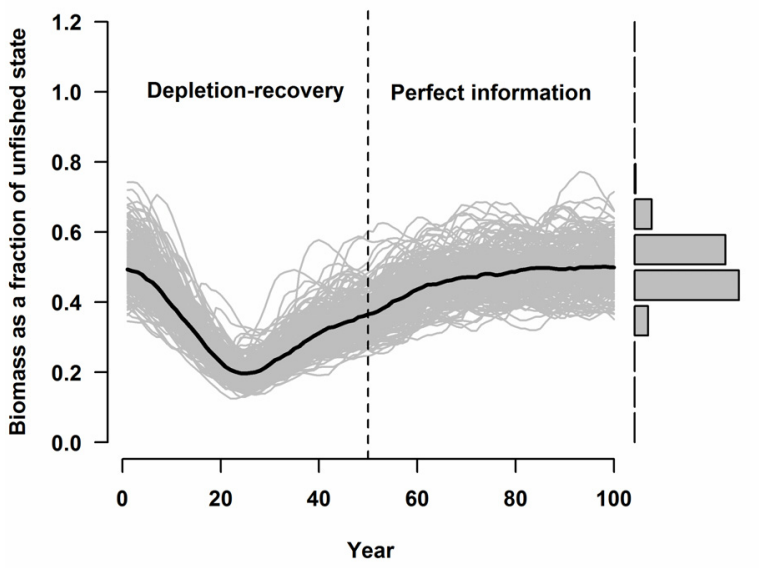

Fig. 5. Simulated perfect information about target fishing effort following a 50-year period of biomass depletion and recovery. Histogram shows distribution of terminal biomass as fractions of unfished state for 200 simulation runs; solid line is median relative biomass.

survey data. Given that fishing effort is proportional to fishing mortality:

$$
F_{\text {target }}=q f_{\text {target }},
$$

and that fishing mortality in the previous year could be estimated as

$$
F_{t-1}=-\log \left(1-Y_{t-1}^{w} / B_{t-1}^{E}\right)=q f_{t-1}
$$

Effort adjustments could be made by re-arranging the two previous equations:

$$
\frac{F_{t-1}}{f_{t-1}}=\frac{F_{\text {target }}}{f_{\text {target }}},
$$

and solving for the value of $f_{\text {target }}$. Total annual effort was set to the resulting target, with the additional conditions that effort increases did not exceed $20 \%$ annually and in instances of model fitting failure, effort was held constant at the previous year's value as a status quo decision.

To put the MSE results into context, we first carried out simulations using perfect information about fishing effort that would produce target biomass of $0.5 B_{0}$ (Fig. 5). This means that rather than using the HCR, fishing effort was set annually to $f_{\text {target}}$, obtained from the 'true' stock dynamics. Using perfect information demonstrated the extent to which fluctuations above and below the target biomass $\left(1 / 2 B_{0}\right)$ would occur because of natural recruitment fluctuations and stochastic growth of individuals that prevent precise control of fish stocks (Hatton et al. 2006; Larkin 1977). The MSY control rule was less effective than the perfect information simulations in guiding biomass towards $0.5 B_{0}$, but avoided undesirable biomass declines (Fig. 6). Survey precision influenced the extent to which biomass declined to undesirably low levels. Under survey $\mathrm{CVs}$ of 0.2 and $0.5,6 \%$ and $13 \%$ of simulation runs fell below $0.2 B_{0}$, respectively. By dissecting MSE outputs, it was 

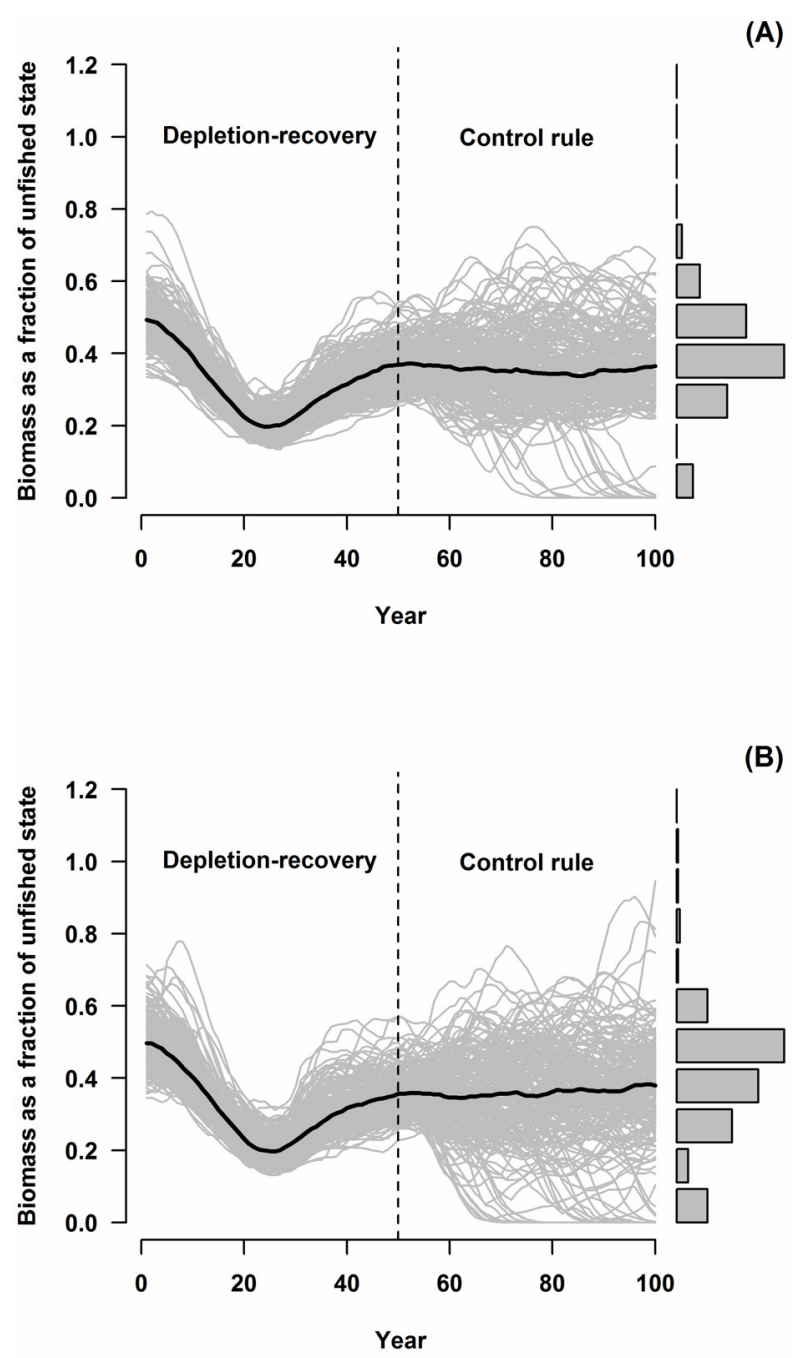

Fig. 6. Simulated MSY control rule informed by fitting routine with survey target CVs of 0.2 (A) and 0.5 (B). Histograms show distribution of terminal biomass as fractions of unfished state for 200 simulation runs; solid line is median relative biomass.

also possible to determine how problems arose in our management system. In simulations where biomass fell below $0.2 B_{0}$, current fishing mortality rates tended to underestimated. Consequently, the control rule increased fishing effort - often in consecutive years - because fishing mortality was incorrectly perceived to be much lower than $F_{M S Y}$. Stock declines were also accelerated through overestimation of stock productivity, as this was a symptom of applying surplus production to a lowproductivity fish stock.

Given survey imprecision, inaccurate stock dynamics using surplus production, and modest performance of the MSY HCR, it seemed appropriate to also consider a more conservative HCR. MSE was repeated using a more precautionary target of $F_{\text {target }}=0.5 F_{M S Y}$. In contrast to the MSY control rule, the precautionary control rule resulted in higher average biomass (Fig. 7). The precautionary control rule resulted in $70 \%$ and $65 \%$ of simulated biomass trends being greater than $0.5 B_{0}$ after 50 simulated years under target survey CVs of 0.2 and 0.5 , respectively; whereas the MSY control rule re-

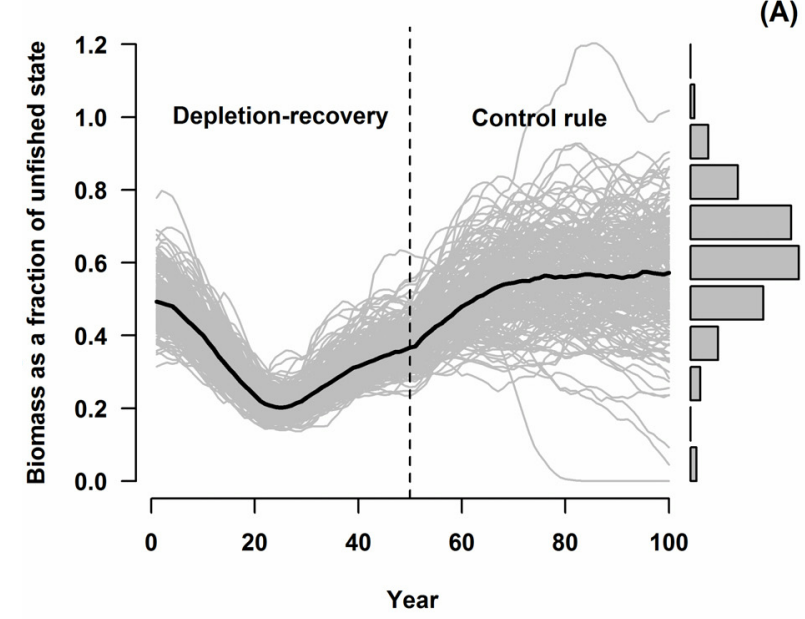

(A)

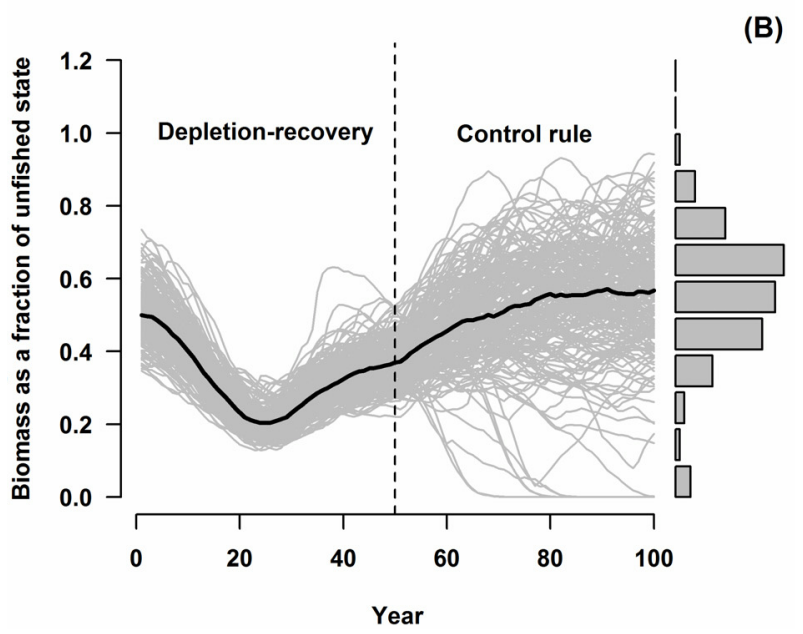

Fig. 7. Simulated precautionary control rule informed by fitting routine with survey target CVs of 0.2 (A) and 0.5 (B). Histograms show distribution of terminal biomass as fractions of unfished state for 200 simulation runs; solid line is median relative biomass.

sulted in $<15 \%$ of simulations above this biomass level. Not surprisingly, protection against the stock becoming overfished was also improved with $<4 \%$ of simulation runs falling below $0.2 B_{0}$ across all survey CVs. Thus, we demonstrated that survey precision affects management strategy performance, but also that realistic constraints on survey precision and stock assessment modeling should contribute to considerations of precaution in setting reference points for fisheries management.

\subsection{An example of a model-free harvest control rule}

For contrast with the assessment-based control rules, a model-free (or empirical) harvest control rule was implemented to reflect a low data method that could be used in the absence of a reliable yield history. Model-free control rules are often based on relative biomass trends and do not incorporate yield data, which would be necessary to scale relative biomass trends to absolute biomass (Apostolaki and 
Hillary 2009). Design of management strategies based upon model-free control rules has received considerable recent attention (De Oliveira and Butterworth 2004; Hilborn et al. 2002; Prince et al. 2011). The straightforward and tractable nature of model-free management strategies has further led to performance comparisons against strategies that rely on complex stock assessment procedures (Geromont and Butterworth 2015a). But model-free control rules have particularly gained acceptance because of their modest data requirements (Carruthers et al. 2015; Geromont and Butterworth 2015b). Model-free control rules have been developed for North Atlantic and Australian fisheries (Cook 2013; Little et al. 2011; Pomarede et al. 2010), and have also been proposed for management of Caribbean conch (Strombus gigas) and spiny lobster (Panulirus argus) fisheries and for coastal Pacific fishery management in conjunction with the use of marine reserves (Babcock and MacCall 2011; McGilliard et al. 2011; MER 2015). In instances where unreliable yield data are not useful in stock assessment, calls have also been made for related approaches to stock assessment and harvest regulation (Mesnil et al. 2009; Porch et al. 2006).

MSE procedure - A simple control rule was formulated that was aimed at (1) maintaining current biomass stability with respect to a historical relative biomass reference point (Apostolaki and Hillary 2009; Hilborn et al. 2002) and (2) avoiding biomass levels associated with overfished status. This example reflects an instance of data limitation where data types (i.e. no catch data) and survey data precision are of management concern. The model-free HCR adjusted effort through the approach developed by Apostolaki and Hillary (2009):

$$
f_{t}=\left(\frac{1}{10} \sum_{j=t-10}^{t-1} f_{j}\right) \gamma_{t},
$$

where a moving-average of the previous 10 years effort levels was adjusted using a multiplicative factor, $\gamma_{t}$. The multiplicative factor was calculated as:

$$
\gamma_{t}=\frac{\frac{1}{10} \sum_{i=t-10}^{t-1} U_{i}}{U_{\text {historic }}}
$$

where $U$ is the moving average relative biomass survey over a period of the previous 10 years, and $U_{\text {historic }}$ is the historical relative biomass reference point. A ten year moving average was selected to control inter-annual effort variation.

MSE results - The model-free control rule performed well even when surveys had target CVs of 0.5 , as biomass fluctuations associated with effort changes were not extreme and rarely trended towards an overfished state (Fig. 8). Slightly poorer biomass stability was associated with surveys with higher target $\mathrm{CV}$, but this control rule fared well at avoiding low biomass levels, with $0 \%$ and $0.5 \%$ of simulations falling below $0.2 B_{0}$ under survey CVs of 0.2 and 0.5 , respectively.

\section{Discussion}

Simulations suggested that balancing survey precision, stock assessment complexity, and the degree of precaution

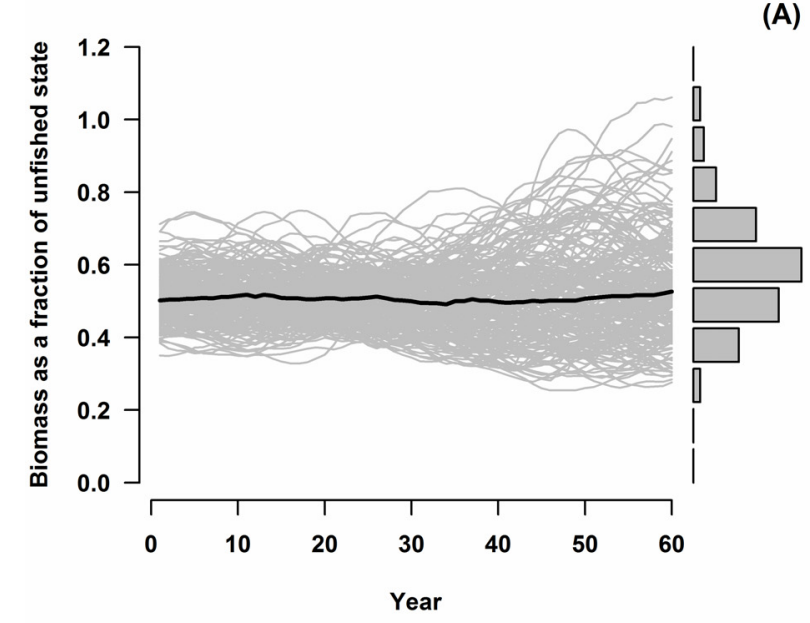

(B)

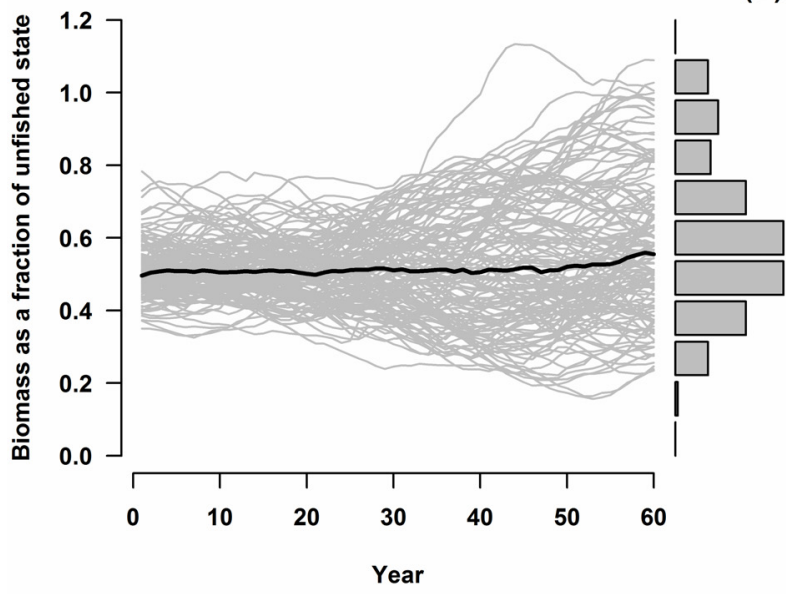

Fig. 8. Simulated model-free control rule with survey target CVs of 0.2 (A) and 0.5 (B). Histograms show distribution of terminal biomass as fractions of unfished state for 200 simulation runs; solid line is median relative biomass.

taken in decision-making are important and interconnected considerations in fisheries management. Simulations incorporated natural process variation through individual growth heterogeneity and through recruitment deviations. Observation error was controlled through sampling intensity, but importantly, decisions about sampling intensity were themselves dependent on previous sampling events, which were subject to imprecision. Consequently, simulated noisy biomass surveys represented biological and sampling processes that separately and successively introduced variation into observed data. This approach perhaps better represented the conditions faced by scientists and managers and avoided the unrealistic presumption that simulated survey trends fluctuate in a simple stochastic manner (Walters and Martell 2004).

In the first example that used a surplus production model, survey precision had a clear role in instances of undesirable biomass declines, as the number of simulation runs where biomass fell below $0.2 B_{0}$ was twice as high for surveys with target CVs of 0.5 as it was for surveys with CVs of 0.2 . 
Simulations also suggested that the assessment procedure itself, regardless of survey precision, contributed to biases in parameter estimation. Contrasting outcomes between example 1 (model-based) and example 2 (model-free or empirical) HCRs was instructive about trade-offs between the extent to which management objectives can be achieved and the types and precision of data inputs that would be required to do so. In the absence of a stock assessment model, the model-free control rule performed well at avoiding undesirable biomass declines. However, performance of the model-free control rule was evaluated against the objective of maintaining historical relative biomass, rather than against MSY-based reference points. This situation raises a relevant policy question about the ways in which management objectives and data availability are interconnected. In some instances, legislative mandates may determine management objectives, and consequently, design of monitoring programs that can best address these objectives. Conversely, limited data availability may constrain the extent to which management objectives can be achieved. Modelbased and model-free approaches also performed differently in terms of yield stability. By examining the final 10 years of each MSE variant, catch stability was compared during periods of relatively stable biomass that were at similar levels of overall stock depletion. Using perfect information about fishing effort that would produce target biomass of $0.5 B_{0}$, interannual variation in yield had a mean CV of 0.04 . In comparison, the MSY control rule produced inter-annual yield variation with mean $\mathrm{CV}$ s of 0.13 and 0.17 for surveys with target CVs of 0.2 and 0.5 , respectively. Inter-annual variation in yield for the precautionary control rule was more in-line with the variation expected from the perfect information control rule (catch CVs 0.05 and 0.07 for survey target CVs of 0.2 and 0.5 , respectively). Without requiring an assessment model, the model-free (or empirical) control rule produced catch stability levels that were similar to model-based HCRs (mean CVs of 0.08 and 0.11 for surveys with CVs of 0.2 and 0.5 , respectively).

Often, data limitations are thought of as a lack of yield and fishing effort histories, biomass indices, or age composition data; all of which are used in stock assessment (Hilborn and Walters 1992). However, when data are available, more subtle aspects of data bias and precision affect how useful data are for informing fisheries management. In ecosystems where highly heterogeneous habitats influence fish distributions, sampling designs must account for this complexity; otherwise, evaluations of stock status and responses to management actions are likely to be inaccurate (Ault et al. 2013; Gerber et al. 2007, 2003; Jennings 2001; Smith et al. 2011). Simulation studies that incorporate spatial heterogeneity in habitat configuration and in fish distribution, like those presented in this study, are uncommon (Meester et al. 2004; Saul et al. 2012). In addition, spatially explicit IBMs are only beginning to be used to evaluate monitoring designs for spatially-structured fish stocks (Thorson et al. 2012). Where previous spatial management evaluations have been conducted, simulation-based approaches have typically represented coastal environments as one-dimensional linear arrays (Babcock and MacCall 2011; Hilborn et al. 2006; Kellner et al. 2007; McGilliard et al. 2011; Ralston and O'Farrell 2008). Through spatially explicit simu- lation, our approach better reflected processes that give rise to variation in survey indices. However, our straight-forward examples did not address fish movement, which is frequently identified as a key management uncertainty where spatial heterogeneity in fishing effort (e.g. marine reserves) influences fish density (Guénette et al. 1998; Meester et al. 2001; Sale et al. 2005). Although reef fish tend to display low movement, larger grouper species sometimes maintain home ranges larger than the $200 \mathrm{~m}$ by $200 \mathrm{~m}$ grid cell that was used in the simulations, and thus, movement effects on monitoring design require additional consideration (Chapman and Kramer 2000; Farmer and Ault 2011).

The use of spatially-explicit simulation frameworks to evaluate strategies for fisheries management that link sampling considerations to decision-making is only beginning to be explored (McDonald et al. 2008; Meester et al. 2001; Sainsbury 1991). There has been considerable study on statistical principles of sampling design, including the strengths and weaknesses of various approaches (Cochran 1977; Manly et al. 2002; Peterman 1990; Thompson and Seber 1996; Walters 1986). But how well fish survey designs translate into information that can accurately inform fisheries management is not as well established. Our examples provided little direct advice on fish stock sampling designs. Instead, we mirror the viewpoints of Houk and van Woesik (2013) and Olsen et al. (1999) that survey design should connect more directly to pertinent resource management questions that need to be addressed. We present this viewpoint in the context of controlling fish harvests and illustrate the end-to-end connection between monitoring and decision-making through MSE. Our conceptual examples demonstrated that MSE can be useful for addressing questions related to data limitations, like: can existing sampling designs be informative enough to avoid the need for additional data collection? And, what management objectives are achievable, given realistic constraints on the data that is available? Thus, we suggest that understanding connections between the subtleties of survey design, quantitative stock assessment, and harvest control rules remains an important multidisciplinary research priority.

Acknowledgements. We thank S.G. Smith and J.S. Ault for advice on reef fish sampling designs. We thank L.R. Little and an anonymous reviewer for offering improvements to the manuscript. Financial support was provided by the Cooperative Institute for Marine and Atmospheric Studies of the University of Miami (NOAA Cooperative Agreement NA10OAR4320143) and by a Natural Sciences and Engineering Research Council of Canada Postgraduate Scholarship to WJH.

\section{References}

Alagaraja K., 1984, Simple methods for estimation of parameters for assessing exploited fish stocks. Indian J. Fish. 31, 177-208.

Alós J., Palmer M., Balle S., Grau A.M., Morales-Nin B., 2010, Individual growth pattern and variability in Serranus scriba: a Bayesian analysis. ICES J. Mar. Sci. 67, 502-512.

Apostolaki P., Hillary R., 2009, Harvest control rules in the context of fishery-independent management of fish stocks. Aquat. Living Resour. 22, 217-224. 
Ault J.S., Smith S.G., Bohnsack J.A., Luo J., Zurcher N., McClellan D.B., Ziegler T.A., Hallac D.E., Patterson M., Feeley M.W., Ruttenberg B.I., Hunt J., Kimball D., Causey B., 2013, Assessing coral reef fish population and community changes in response to marine reserves in the Dry Tortugas, Florida, USA. Fish. Res. $144,28-37$

Babcock E.A., MacCall A.D., 2011, How useful is the ratio of fish density outside versus inside no-take marine reserves as a metric for fishery management control rules? Can. J. Fish. Aquat. Sci. 68, 343-359.

Bunnell D.B., Miller T.J., 2005, An individual-based modeling approach to spawning-potential per-recruit models: an application to blue crab (Callinectes sapidus) in Chesapeake Bay. Can. J. Fish. Aquat. Sci. 62, 2560-2572.

Butterworth D.S., Punt A.E., 1999, Experiences in the evaluation and implementation of management procedures. ICES J. Mar. Sci. J. Cons. 56, 985-998.

Butterworth D.S., Bentley N., Oliveira J.A.A.D., Donovan G.P., Kell L.T., Parma A.M., Punt A.E., Sainsbury K.J., Smith A.D.M., Stokes T.K., 2010, Purported flaws in management strategy evaluation: basic problems or misinterpretations? ICES J. Mar. Sci. $67,567-574$

Carruthers T.R., Kell L.T., Butterworth D.D.S., Maunder M.N., Geromont H.F., Walters C., McAllister M.K., Hillary R., Levontin P., Kitakado T., Davies C.R., 2015, Performance review of simple management procedures. ICES J. Mar. Sci. J. Cons. fsv212.

Chapman M.R., Kramer D.L., 1999, Gradients in coral reef fish density and size across the Barbados Marine Reserve boundary: effects of reserve protection and habitat characteristics. Mar. Ecol. Prog. Ser. 181, 81-96.

Chapman M.R., Kramer D.L., 2000, Movements of fishes within and among fringing coral reefs in Barbados. Environ. Biol. Fishes 57, $11-24$.

Cochran W.G., 1977, Sampling Techniques, 3rd edn. John Wiley \& Sons, New York.

Codling E.A., 2008, Individual-based movement behaviour in a simple marine reserve - fishery system: why predictive models should be handled with care. Hydrobiologia 606, 55-61.

Cook R.M., 2013, A fish stock assessment model using survey data when estimates of catch are unreliable. Fish. Res. 143, 1-11.

Cope J.M., Punt A.E., 2009, Length-based reference points for datalimited situations: applications and restrictions. Mar. Coast. Fish. 1, 169-186.

DeAngelis D.L., Godbout L., Shuter B.J., 1991, An individual-based approach to predicting density-dependent dynamics in smallmouth bass populations. Ecol. Model. 57, 91-115.

De Oliveira J.A.A., Butterworth D.S., 2004, Developing and refining a joint management procedure for the multispecies South African pelagic fishery. ICES J. Mar. Sci. J. Cons. 61, 1432-1442.

Dowling N.A., Dichmont C.M., Haddon M., Smith D.C., Smith A.D.M., Sainsbury K., 2015, Empirical harvest strategies for data-poor fisheries: A review of the literature. Fish. Res. 171, 141-153.

Farmer N., Ault J., 2011, Grouper and snapper movements and habitat use in Dry Tortugas, Florida. Mar. Ecol. Prog. Ser. 433, 169-184.

Fournier D.A., Skaug H.J., Ancheta J., Ianelli J., Magnusson A., Maunder M.N., Nielsen A., Sibert J., 2012, AD Model Builder: using automatic differentiation for statistical inference of highly parameterized complex nonlinear models. Optim. Methods Softw. 27, 233-249.

Gerber L.R., Botsford L.W., Hastings A., Possingham H.P., Gaines S.D., Palumbi S.R., Andelman S., 2003, Population models for marine reserve design: a retrospective and prospective synthesis. Ecol. Appl. 13, 47-64.

Gerber L.R., Wielgus J., Sala E., 2007, A decision framework for the adaptive management of an exploited species with implications for marine reserves. Conserv. Biol. 21, 1594-1602.

Geromont H.F., Butterworth D.S., 2015a, Complex assessments or simple management procedures for efficient fisheries management: a comparative study. ICES J. Mar. Sci. 72, 262-274.

Geromont H.F., Butterworth D.S., 2015b, Generic management procedures for data-poor fisheries: forecasting with few data. ICES J. Mar. Sci. 72, 251-261.

Grimm V., Berger U., Bastiansen F., Eliassen S., Ginot V., Giske J., Goss-Custard J., Grand T., Heinz S.K., Huse G., Huth A., Jepsen J.U., Jørgensen C., Mooij W.M., Müller B., Pe'er G., Piou C., Railsback S.F., Robbins A.M., Robbins M.M., Rossmanith E., Rüger N., Strand E., Souissi S., Stillman R.A., Vabø R., Visser U., DeAngelis D.L., 2006, A standard protocol for describing individual-based and agent-based models. Ecol. Model. 198, $115-126$.

Guénette S., Lauck T., Clark C., 1998, Marine reserves: from Beverton and Holt to the present. Rev. Fish Biol. Fish. 8, 251272.

Harford W.J., 2014, Integrated monitoring and stock assessment of spatially heterogeneous reef fisheries (Dissertation). Miami, Florida, USA, University of Miami.

Harford W.J., Smith S.G., Ault J.S., Babcock E.A., 2015, Crossshelf habitat occupancy probabilities for juvenile groupers in the Florida Keys coral reef ecosystem. Mar. Coast. Fish. 8, 147-159.

Hart D.R., 2001, Individual-based yield-per-recruit analysis, with an application to the Atlantic sea scallop, Placopecten magellanicus. Can. J. Fish. Aquat. Sci. 58, 2351-2358.

Hatton I.A., McCann K.S., Umbanhowar J., Rasmussen J.B., 2006, A dynamical approach to evaluate risk in resource management. Ecol. Appl. 16, 1238-1248.

Hertz D.B., Thomas H., 1983, Risk analysis and its applications. Wiley, New York.

Hilborn R., 1979, Comparison of fisheries control systems that utilize catch and effort data. J. Fish. Res. Board Can. 36, 1477-1489.

Hilborn R., Walters C., 1992, Quantitative fisheries stock assessment: choice, dynamics, and uncertainty. N.Y., Chapman and Hall, New York.

Hilborn R., Parma A., Maunder M., 2002, Exploitation rate reference points for west coast rockfish: are they robust and are there better alternatives? North Am. J. Fish. Manag. 22, 365-375.

Hilborn R., Micheli F., De Leo G.A., 2006, Integrating marine protected areas with catch regulation. Can. J. Fish. Aquat. Sci. 63, 642-649.

Houk P., van Woesik R., 2013, Progress and perspectives on questiondriven coral-reef monitoring. Bioscience 63, 297-303.

Huse G., 2001, Modelling habitat choice in fish using adapted random walk. Sarsia 86, 477-483.

Huse G., Giske J., 1998, Ecology in Mare Pentium: an individualbased spatio-temporal model for fish with adapted behaviour. Fish. Res. 37, 163-178.

Jennings S., 2001, Patterns and prediction of population recovery in marine reserves. Rev. Fish Biol. Fish. 10, 209-231.

Keitt T.H., 2000, Spectral representation of neutral landscapes. Landsc. Ecol. 15, 479-494.

Kellner J.B., Tetreault I., Gaines S.D., Nisbet R.M., 2007, Fishing the line near marine reserves in single and multispecies fisheries. Ecol. Appl. 17, 1039-1054.

Larkin P.A., 1977, An epitaph for the concept of maximum sustained yield. Trans. Am. Fish. Soc. 106, 1-11. 
Little L.R., Wayte S.E., Tuck G.N., Smith A.D.M., Klaer N., Haddon M., Punt A.E., Thomson R., Day J., Fuller M., 2011, Development and evaluation of a cpue-based harvest control rule for the southern and eastern scalefish and shark fishery of Australia. ICES J. Mar. Sci. J. Cons. 68, 1699-1705.

Li X., He H.S., Wang X., Bu R., Hu Y., Chang Y., 2004, Evaluating the effectiveness of neutral landscape models to represent a real landscape. Landsc. Urban Plan. 69, 137-148.

Lorenzen K., 1996, The relationship between body weight and natural mortality in juvenile and adult fish: a comparison of natural ecosystems and aquaculture. J. Fish. Biol. 49, 627-647.

Luke S., Cioffi-Revilla C., Panait L., Sullivan K., Balan G., 2005, MASON: a multi-agent simulation environment. Simulation 82, 517-527.

Magnusson A., Hilborn R., 2007, What makes fisheries data informative? Fish. Fish. 8, 337-358.

Manly B.F., McDonald L., Thomas D.L., McDonald T.L., Erickson W.P., 2002, Resource Selection by Animals: Statistical Design and Analysis for Field Studies, 2nd edition. Springer.

Martell S., Froese R., 2012, A simple method for estimating MSY from catch and resilience. Fish Fish. DOI: 10.1111/j . 1467-2979.2012.00485.x.

McDonald A.D., Little L.R., Gray R., Fulton E., Sainsbury K.J., Lyne V.D., 2008, An agent-based modelling approach to evaluation of multiple-use management strategies for coastal marine ecosystems. Math. Comput. Simul. 78, 401-411.

McGilliard C.R., Hilborn R., MacCall A., Punt A.E., Field J.C., 2011, Can information from marine protected areas be used to inform control-rule-based management of small-scale, data-poor stocks? ICES J. Mar. Sci. J. Cons. 68, 201-211.

Meester G.A., Ault J.S., Smith S.G., Mehrotra A., 2001, An integrated simulation modeling and operations research approach to spatial management decision making. Sarsia 86, 543-558.

Meester G.A., Mehrotra A., Ault J.S., Baker E.K., 2004, Designing marine reserves for fishery management. Manag. Sci. 50, 10311043.

MER, 2015, A Management Strategy Evaluation of a Multi-Indicator Adaptive Management Framework for Data-Poor Fisheries. MER Consultants, submitted to The Nature Conservancy May 5, 2015.

Mesnil B., Cotter J., Fryer R.J., Needle C.L., Trenkel V.M., 2009, A review of fishery-independent assessment models, and initial evaluation based on simulated data. Aquat. Living Resour. 22, 207-216.

Miethe T., Pitchford J., Dytham C., 2009, An individual-based model for reviewing marine reserves in the light of fisheries-induced evolution in mobility and size at maturation. J. Northwest Atl. Fish. Sci. 41, 151-162.

Mohn R.K., 1980, Bias and error propagation in logistic production models. Can. J. Fish. Aquat. Sci. 37, 1276-1283.

Olsen A.R., Sedransk J., Edwards D., Gotway C.A., Liggett W., Rathbun S., Reckhow K.H., Yyoung L.J., 1999, Statistical Issues for Monitoring Ecological and Natural Resources in the United States. Environ. Monit. Assess. 54, 1-45.

Peitgen H.-O., Saupe D. (Eds.), 1988, The Science of Fractal Images. Springer-Verlag, New York.

Pelletier D., Mahévas S., 2005, Spatially explicit fisheries simulation models for policy evaluation. Fish Fish. 6, 307-349.

Peterman R.M., 1990, Statistical power analysis can improve fisheries research and management. Can. J. Fish. Aquat. Sci. 47, 2-15.

Pomarede M., Hillary R., Ibaibarriaga L., Bogaards J., Apostolaki P., 2010, Evaluating the performance of survey-based operational management procedures. Aquat. Living Resour. 23, 77-94.
Porch C.E., Eklund A.-M., Scott G.P., 2006, A catch-free stock assessment model with application to goliath grouper (Epinephelus itajara) off southern Florida. Fish. Bull. 104, 89-101.

Prince J.D., Dowling N.A., Davies C.R., Campbell R.A., Kolody D.S., 2011, A simple cost-effective and scale-less empirical approach to harvest strategies. ICES J. Mar. Sci. 68, 947-960.

Punt A.E., Butterworth D.S., de Moor C.L., De Oliveira J.A.A., Haddon M., 2014, Management strategy evaluation: best practices. Fish Fish. n/a-n/a.

Railsback S.F., Lamberson R.H., Harvey B.C., Duffy W.E., 1999, Movement rules for individual-based models of stream fish. Ecol. Model. 123, 73-89.

Ralston S., O'Farrell M.R., 2008, Spatial variation in fishing intensity and its effects on yield. Can. J. Fish. Aquat. Sci. 65, 588-599.

R Development Core Team, 2012, R: A Language and Environment for Statistical Computing, Vienna, Austria http://www.Rproject.org. Vienna, Austria.

Richards B.L., Williams I.D., Nadon M.O., Zgliczynski B.J., 2011, A Towed-Diver Survey Method for Mesoscale Fishery-Independent Assessment. Bull. Mar. Sci. 87, 55-74.

Rose K.A., Rutherford E.S., McDermot D.S., Forney J.L., Mills E.L., 1999, Individual-based model of yellow perch and walleye populations in Oneida Lake. Ecol. Monogr. 69, 127-154.

Russo T., Mariani S., Baldi P., Parisi A., Magnifico G., 2009, Progress in modelling herring populations: an individual-based model of growth. ICES J. Mar. Sci. 66, 1718-1725.

Sainsbury K.J., 1991, Application of an experimental approach to management of a tropical multispecies fishery with highly uncertain dynamics. ICES J. Mar. Sci. Symp. 193, 301-320.

Sainsbury K., Punt A.E., Smith A.D.M., 2000, Design of operational management strategies for achieving fishery ecosystem objectives. ICES J. Mar. Sci. 57, 731-741.

Sale P.F., Cowan R.K., Danilowicz B.S., Jones G.P., Kritzer J.P., Lindeman K.C., Planes S., Polunin N.V.C., Russ G.R., Sadovy Y.J., Steneck R.S., 2005, Critical science gaps impede use of notake fishery reserves. Trends Ecol. Evol. 20, 74-80.

Saul S., Die D., Brooks E.N., Burns K., 2012, An individual-based model of ontogenetic migration in reef fish using a biased random walk. Trans. Am. Fish. Soc. 141, 1439-1452.

Schaefer M.B., 1954, Some aspects of the dynamics of populations important to the management of the commercial marine fisheries. Inter-Am Trop Tuna Comm Bull 1, 27-56.

Schlather M., Menck P., Singleton R., Pfaff B., R Core Team, 2013, RandomFields: Simulation and Analysis of Random Fields. R package version 2.0.66. http://CRAN.R-project.org/ package $=$ RandomFields.

SEDAR, 2010, Stock assessment report: Gulf of Mexico and South Atlantic Black Grouper. South Atlantic Fishery Management Council. SEDAR 19.

Sluka R., Chiappone M., Sealey K.M.S., 2001, Influence of habitat on grouper abundance in the Florida Keys, USA. J. Fish Biol. 58, 682-700.

Smith S.G., Ault J.S., Bohnsack J.A., Harper D.E., Luo J., McClellan D.B., 2011, Multispecies survey design for assessing reef-fish stocks, spatially-explicit management performance, and ecosystem condition. Fish. Res. 109, 25-41.

Stein M.L., 2002, Fast and exact simulation of fractional Brownian surfaces. J. Comput. Graph. Stat. 11, 587.

Thompson S.K., 2012, Sampling, Wiley series in probability and statistics, 3rd edition. Wiley, Hoboken, N.J.

Thompson S.K., Seber G.A.F., 1996, Adaptive Sampling. John Wiley \& Sons, Inc, New York. 
Thorson J.T., Stewart I.J., Punt A.E., 2012, Development and application of an agent-based model to evaluate methods for estimating relative abundance indices for shoaling fish such as Pacific rockfish (Sebastes spp.). Ices J. Mar. Sci. 69, 635-647.

Train K.E., 2002, Discrete Choice Methods with Simulation. 2nd edition, Cambridge University Press.

Tyler J.A., Rose K.A., 1994, Individual variability and spatial heterogeneity in fish population models. Rev. Fish Biol. Fish. 4, 91123.

van Winkle W., Jager H.I., Railsback S.F., Holcomb B.D., Studley T.K., Baldrige J.E., 1998, Individual-based model of sympatric populations of brown and rainbow trout for instream flow assessment: model description and calibration. Ecol. Model. 110, 175207. von Bertalanffy L., 1938, A quantitative theory of organic growth (Inquiries on growth laws II). Hum. Biol 10, 181-213.

Walters C., 1986, Adaptive Management of Renewable Resources. MacMillan Publishing Company, New York.

Walters C.J., Martell S.J.D., 2004, Fisheries Ecology and Management. Princeton University Press, USA.

Walters C., Ludwig D., 1994, Calculation of Bayes posterior probability distributions for key population parameters. Can. J. Fish. Aquat. Sci. 51, 713-722.

With K.A., King A.W., 1997, The use and misuse of neutral landscape models in ecology. Oikos 79, 219-229.

Zhang Z., 2013, Evaluation of logistic surplus production model through simulations. Fish. Res. 140, 36-45. 